\title{
XPS Study of Corrosion Deposit in Stainless Steel Hardfacing
}

\author{
E. Huape-Padilla ${ }^{1}$, L. Béjar-Gómez ${ }^{1}$, M. Sanchez-Carrillo², A. Medina-Flores ${ }^{3}$, H.G. Carreón-
} Garcidueñas $^{3}$, S. E. Borjas-García ${ }^{4}$ and R. Huirache-Acuña ${ }^{5}$

1. Facultad de Ingeniería Mecánica, Universidad Michoacana de San Nicolás de Hidalgo, Morelia, Mich., México.

2. Universidad Tecnológica de Chihuahua Sur, Chihuahua. Chih. México.

3. Instituto de Investigación en Metalurgia y Materiales. Universidad Michoacana de San Nicolás de Hidalgo, Morelia, Mich., México.

4. Instituto de Física y Matemáticas, Universidad Michoacana de San Nicolás de Hidalgo, Morelia, Michoacán, México.

5. Facultad de Ingeniería Química, Universidad Michoacana de San Nicolás de Hidalgo, Morelia, Michoacán, México.

Hardfacing is a widely used method to service life extensión of the surfaces in continuous caster rolls subjected to severe wear, corrosion or oxidation. Martensitic stainless steels within the $12 \%$ chromium alloys are the most used steels to hardfacing, nitrogen can be added to for cladding applications as an to carbon sustitute to increase hardness and form austenite at elevated temperatures [1,2]. The Heat input (HI) is one of the important variables refers to quality of the welding. Due to the heat input and the slow cooling rate occurs after welding, detrimental residual stresses are generated to the mechanical properties and / or corrosion in service. The leading steel companies in the world are located in coastal areas, where the continuous caster rolls are subject to corrosive environments as seawater. This work studies electrochemical corrosion behavior of martensitic stainless steels in synthetic seawater deposited as hardfacing, weldment have been obtained using an automatic flux-cored arc welding process (FCAW). The rolls were surfaced with a $414 \mathrm{~N}-\mathrm{O}$ tubular wire, a nitrogen-bearing, low-carbon wire that produces a martensitic deposit with a composition optimized for corrosion resistance. Figure 1, shows EDS result after the electrochemical test in seawater, can be seen of product obtained has concentrations of oxygen, chromium and iron. Figure 2, shows XPS result of corrosión products, where can see shape and composition of $\mathrm{O}$ 1s core-level spectra, presence of oxide, (oxy)-hydroxide, and water can be deduced from $\mathrm{O}$ 1s peak fit. Peaks at $\sim 540 \mathrm{eV}$ originate from molecular oxygen $\left(\mathrm{O}_{2}\right)$ due to ambient air. Shape of Fe 2p core-level spectra, where presence of oxide, (oxy)-hydroxide, and metallic iron can be deduced from $\mathrm{Fe} 2 \mathrm{p}_{3 / 2}$. Shape of $\mathrm{Cr} 2 \mathrm{p}$ core-level spectra, where presence of oxide, hydroxide, and metallic $\mathrm{Cr}^{0} \mathrm{can}$ be deduced from $\mathrm{Cr} 2 \mathrm{p}_{3 / 2}$ [3]. Can be concluded that $\mathrm{Fe}$ is found as oxide while oxy-hydroxides appear combined with $\mathrm{Cr}$ and $\mathrm{Fe}$.

\section{References:}

[1] Agustín Gualco et al, Materials and Design 31 (2010), p. 4165.

[2] Madeleine Du Toit and Johan Van Niekerk, Welding in the World 54 (2010), p. 342.

[3] Mark C. Biesinger et al, Applied Surface Science 257 (2011), p. 2717. 


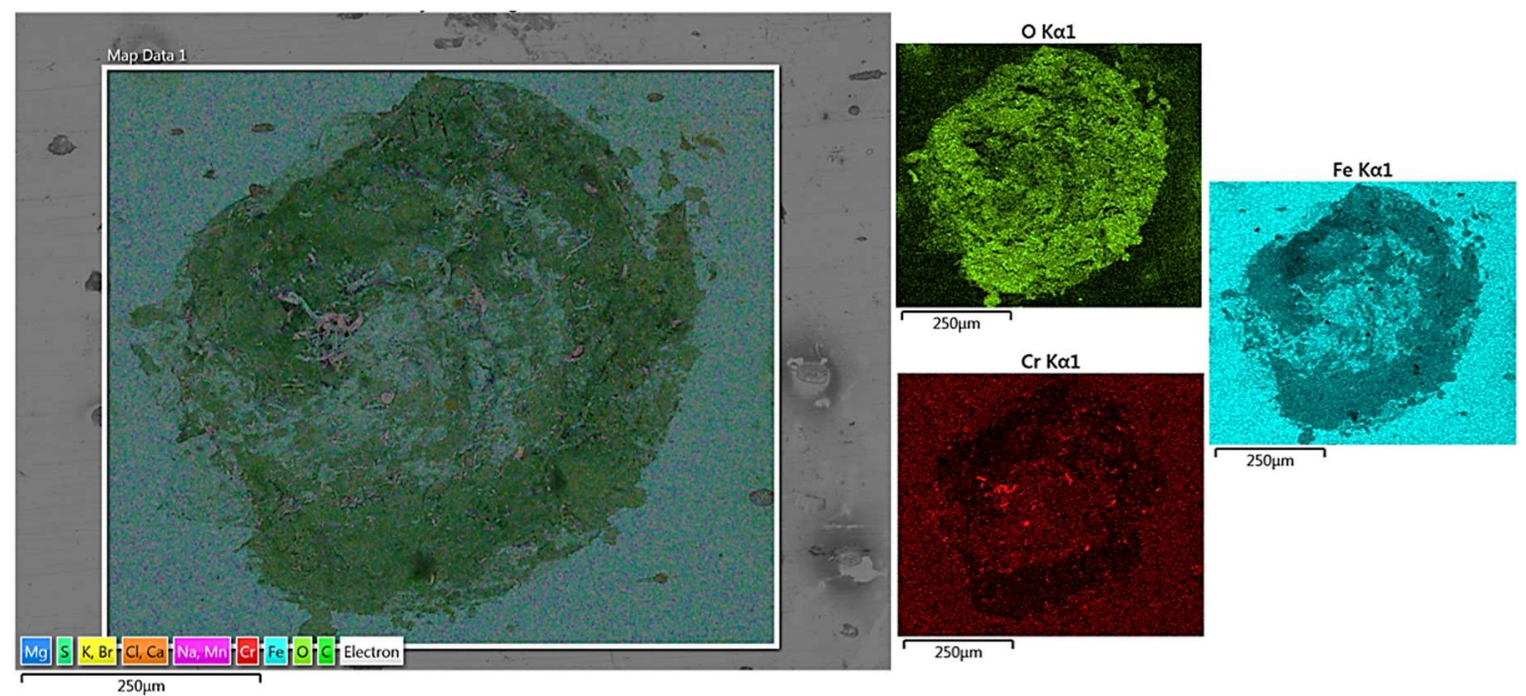

Figure 1. SEM-EDS general result after the electrochemical test in seawater.
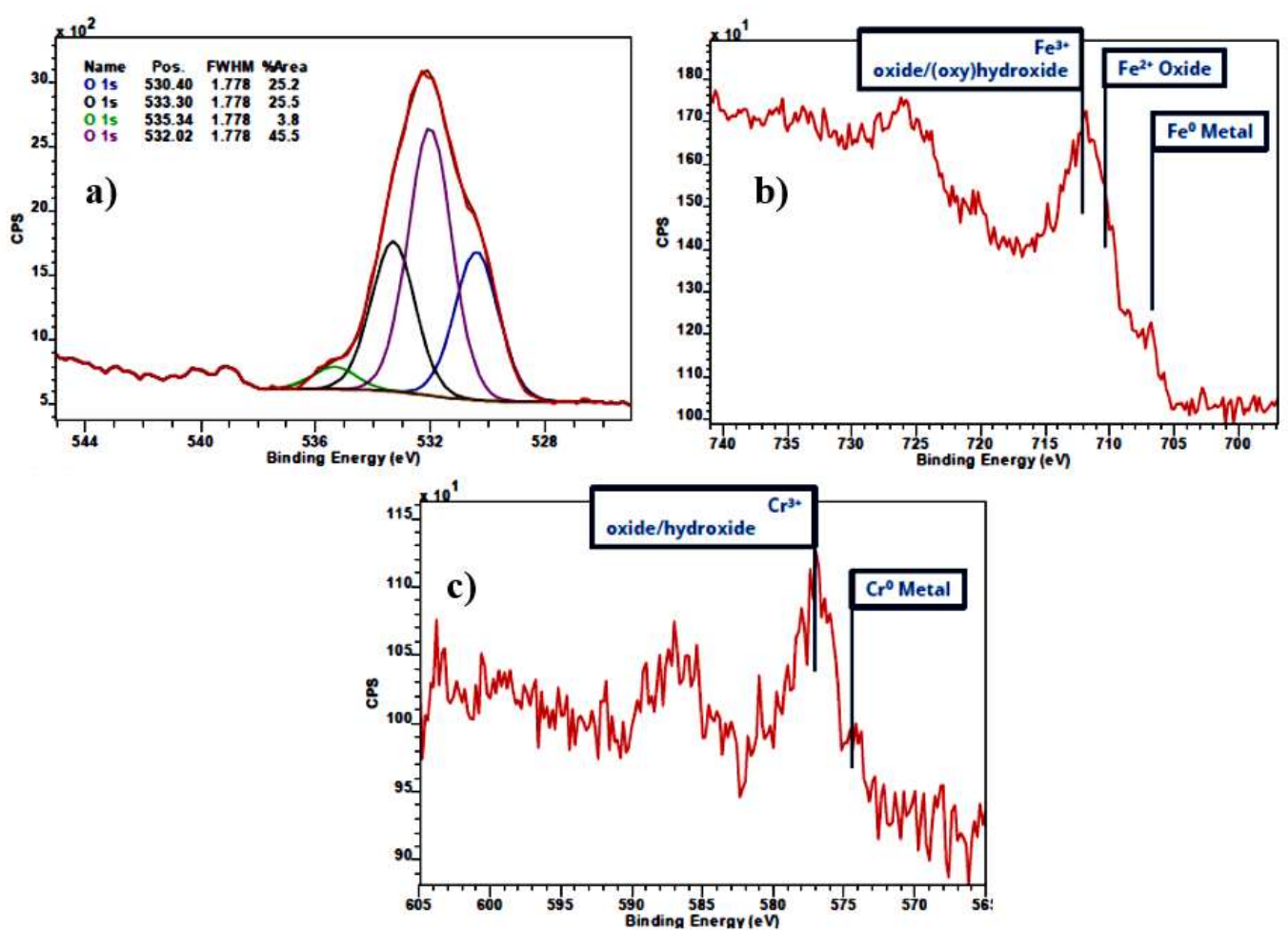

Figure 2. XPS results of: a) O 1s detail spectra, b) Fe 2p detail spectra and c) Cr 2p detail spectra. 